\title{
INTERTEXTUALIDAD, INTERDISCURSIVIDAD Y RETÓRICA CULTURAL ${ }^{1}$
}

\author{
Juan Carlos GÓMEZ ALONSO \\ Universidad Autónoma de Madrid \\ juanc.gomezalonso@uam.es
}

\begin{abstract}
Tosé Enrique Martínez Fernández publicó el libro titulado La intertextualidad literaria (Base teórica y práctica textual) (Martínez, 2001) que ha sido acogido por la crítica académica y universitaria como libro de referencia y de consulta en la bibliografía básica de los estudios y
\end{abstract} materias de Teoría de la Literatura y Literatura Comparada. La claridad expositiva de este libro, su organización y su práctica y crítica literarias son ejemplo de un trabajo riguroso y sirven para que estudiantes y profesores encuentren materiales y ejemplos para las discusiones académicas sobre un concepto (la intertextualidad) que en los últimos años se ha desarrollado de manera extraordinaria. La intertextualidad no es un concepto nuevo sino expresión nueva de una realidad de la Literatura y de la crítica y teoría literarias desde siempre. Pero libros como el mencionado del profesor Martínez Fernández han venido a revitalizar este concepto que en los últimos años podemos ver en muchos títulos de tesis doctorales, trabajos de fin de grado y trabajos de fin de máster. En este libro, José Enrique Martínez Fernández tiene en cuenta las posturas de Kristeva, Pavlicic, Genette, Quintana Docio, Doležel, Guillén, Maestro, entre otros, y desarrolla conceptos fundamentales y propios del estudio de la intertextualidad como la tipología textual, las fuentes e influencias, la cita y la alusión, el discurso dialógico, las cuestiones de la recepción, la huella y la interferencia, precisando su concepto de intertextualidad y deslingándolo de otro tipo de relaciones entre textos de nivel macroestructural, ya que en su trabajo se centra fundamentalmente en los aspectos microestructurales de los textos y en especial del género lírico.

La descripción de la intertextualidad como la acción de unos textos en la génesis de otros textos y sobre los mecanismos de cómo actúan estos textos entre sí ha hecho que cobre mucha importancia en los estudios literarios en general y en los estudios de Teoría del Texto, en particular. El fenómeno de la intertextualidad está relacionado con conceptos tradicionales como son los de imitación, tradición o fuente literaria, entre otros, pero en los siglos XX y XXI ha ido de la mano de un fenómeno tan

\footnotetext{
${ }^{1}$ Este trabajo es resultado de la investigación realizada en el proyecto METAPHORA (Referencia FFI2014-53391-P), proyecto de investigación financiado por la Secretaría de Estado de Investigación, Desarrollo e Innovación.
} 
importante como el de la transducción de Lubomír Doležel, que también ha sido estudiado de manera intensa por Gérard Genette, Tomás Albaladejo, Julia Kristeva y José Enrique Martínez Fernández, entre otros autores. La presencia de conexiones transversales entres distintos textos atendiendo a los niveles fonofonológicos, morfológicos, sintácticos y semánticos, así como los referenciales, implica que la intertextualidad está presente y puede ser estudiada en los textos en todos los niveles textuales, tanto en la microestructura como en la macroestructura. Se trata de un diálogo entre los textos, como señala Julia Kristeva en su libro El texto de la novela:

Así, para estudiar la estructuración de la novela como una transformación, la consideraremos como un DIÁLOGO de múltiples textos, como un DIÁLOGO TEXTUAL, o, mejor dicho, como una INTERTEXTUALIDAD. [...] La noción de transformación diacrónica nos va a permitir, por un lado, definir la especificidad del discurso llamado literario como una intertextualidad (Kristeva, 1974: 94).

Desde que J. Kristeva introdujera, en 1967, este término y determinara el concepto en su conocidísimo artículo sobre M. Bajtin (Kristeva, 1967), la intertextualidad se ha convertido en un fenómeno de la crítica literaria y en un elemento dinamizador de los trabajos de teoría de la literatura y de literatura comparada. La multitud de estudios que se han realizado desde entonces partiendo de las aportaciones de M. Bajtin al carácter dialógico del texto o del discurso, entendiendo éste en una dicotomía entre el carácter polifónico de voces ajenas al narrador y del carácter monológico con el que éstas se enfrentan, ha supuesto una revitalización del fenómeno de la intertextualidad que ya no se circunscribe solamente al texto lingüístico, ni al texto literario, sino que se adentra en otras manifestaciones artísticas con códigos semióticos diferentes a los lingüísticos (pintura, cine, etc.). Así, en los últimos años, venimos entendiendo la intertextualidad ampliada a todas las manifestaciones del arte y analizando los textos objeto de estudio tomando la intertextualidad como presencia efectiva de unos textos en otros, marcados mediante alusiones o citas, marcadas o no marcadas, ya sean endoliterarias o exoliterarias (Martínez, 2001: 81), o bien entendiéndola como una cualidad de todo texto, que en realidad sería (según su propia etimología) un tejido de muchos otros textos, de manera consciente o inconsciente, transformándolos o manteniéndolos en el texto de destino o final.

Relación inevitable con el desarrollo del fenómeno de la intertextualidad tiene también la propuesta que realizaran R. Barthes y M. Foucault (Barthes 1988; Foucault 1979) cuando hablaron o plantearon la cuestión de la 'muerte del autor'. La expresión el autor ha muerto supone una contaminación de significados a través de muchos subtextos que hace que nos planteemos la imposibilidad de la autoría real, dado que todos los textos están permeados de otros textos que impiden que haya una fuente inventiva única y determinada en una obra concreta. De ahí se han derivado muchas corrientes de pensamiento y teorías que la crítica literaria ha adoptado y aplicado a su objeto de estudio, especialmente los trabajos dedicados a analizar el fenómeno de las traducciones literarias, de las adaptaciones y de las reescrituras de obras de la literatura, ya en el mismo marco semiológico, ya en otro sistema semiótico.

Deudor también del concepto y del fenómeno de la intertextualidad es el marco teórico que propone y emplea para la clasificación de los textos G. Genette en Palimpsestos (1989). Como señalaré 
luego el estudio taxonómico de esta obra está en la base del desarrollo del concepto de interdiscursividad, con conceptos como los de transtextualidad y de architextualidad presentes en este fenómeno interdiscursivo y que permiten diferenciar los distintos planos de relación de los textos, así como los distintos tipos de textos.

Antonio Gómez-Moriana (1997) también ha utilizado este concepto y ha demostrado el valor operativo de la intertextualidad en sus trabajos. Y Tomás Albaladejo, como ampliaré después, ha propuesto el análisis interdiscursivo, basado en la interdiscursividad y se ha ocupado de la interdiscursividad como un fenómeno que engloba distintas posibilidades de relación entre textos/discursos, una de las cuales es la intertextualidad.

Ludomír Doležel también plantea la intertextualidad como una cualidad superficial de los textos, propiamente intensional, que se ve reflejada en el plano sintagmático de las obras por medio de citas, frases hechas, estructuras paralelísticas y léxico concreto. Esta concepción es puramente intensional pero no atiende al plano extensional de la obra, como lo relacionado con la construcción de los mundos posibles, la ficcionalidad o la construcción de géneros, ya que Doležel estudia estos aspectos desde la transducción literaria (Doležel, 1995: 282-283). En la traducción, los traductores no son capaces de reproducir minuciosamente todos los elementos intensionales de las obras originales con las mismas estructuras y formas expresivas, pero sí que pueden adecuar su obra traducida a la estructura extensional propuesta en la obra original. De la descripción que hace este autor de la traducción se pueden obtener aportaciones útiles para la manera en la que pueden ser estudiadas también las adaptaciones y las reescrituras de los textos (Doležel, 1995: 286).

En los últimos años estamos viendo cómo el fenómeno de la reescritura y de la adaptación prolifera en nuestra cultura occidental después de haber asumido la muerte del autor como algo connatural a la obra artística. Por un lado, esta labor está reescribiendo la tradición en un contexto de modernidad, ante una cultura y un receptor nuevo y diverso; y, por otro lado, hay una tendencia a no dejar que muera el autor, que en algunas ocasiones tal vez nunca existió, y al que se pretende rescatar del olvido. En este sentido es llamativa la gran cantidad de adaptaciones y reescrituras de las obras clásicas, en general, y de las homéricas, en particular, en la actualidad, como muy bien ha estudiado José Antonio de la Riva Fort en su tesis doctoral titulada Género literario y reescrituras contemporáneas de la épica homérica, defendida en la UAM en 2016. Estamos en una época en la que los autores tienen conciencia de esta situación planteada por R. Barthes y M. Foucault y, por ese motivo, son conscientes de la influencia, con ansiedad, como señalara H. Bloom (2011; 2013); son conscientes de la incapacidad de originalidad total y no pretenden ser absolutamente originales ni modernos; más bien, asumen que sus obras se encuentran inmersas en una serie de redes intertextuales que les llevará, inevitablemente, a reescribir lo ya existente, sea más o menos conocido por el receptor. El autor asume la reescritura como algo connatural a la creación y el receptor, consciente de esto mismo, valora este fenómeno teniendo en cuenta el grado de explicitud de estas relaciones intertextuales en cada caso, sabiendo que tras cada nueva propuesta hay acciones de reescritura o adaptación de una o de varias obras originales que, a su vez, se encuentran integradas en una tradición 
a la que sucumben. Lo que queda por determinar en cada caso de reescritura es la originalidad de la propuesta nueva. Si tenemos en cuenta la propuesta de Panzieri (1996: 37), lo central en la literatura de hoy es reciclar los temas y materiales lingüísticos y cambiar los géneros literarios, siguiendo la función ecológica que le otorga este autor al posmodernismo. Ello lleva al hibridismo literario actual, consciente de que ya no es solamente importante manifestar ideas o proponer expresiones y formas nuevas, sino marcar esas relaciones intertextuales más o menos explícitamente. Esto no quiere decir que toda la producción literaria esté marcada por esta transfusión perpetua que lleve a autores y receptores a una sospecha y ansiedad continua, sino que el movimiento literario, y el artístico en general, tiene como base tradicional una situación palimpsestuosa que lo enmarca y envuelve, en un mosaico de significantes y de significados, que están en la base de todo texto y de toda recepción de las obras. Estos textos adquieren un mayor significado, podríamos decir que pleno, si su significado se obtiene a partir del propio texto, pero activando los mecanismos que estudien sus relaciones con la cultura y con la sociedad en la que se enmarcan, como señalaremos más adelante al referirnos a la Retórica Cultural.

En este sentido se pueden destacar dos obras recientes que ofrecen una visión actualizada sobre la intertextualidad y sobre el fenómeno de la interpretación de las obras y de la deconstrucción: por un lado, Adaptation and appropriation (2008) de Julie Sanders; y, por otro lado, Intertextuality (2010) de Graham Allen. Ambas obras tienen en cuenta el panorama teórico esbozado antes por autores como J. Kristeva, R. Barthes, G. Genette, J. Derrida o M. Foucault y se centran en el fenómeno de la intertextualidad al ocuparse de los motivos culturales y políticos de la reescritura y de la adaptación teniendo en cuenta las múltiples maneras en la que se han recreado las obras canónicas, desde la influencia de movimientos críticos como el postestructuralismo, el poscolonialismo y los estudios de género. Estas obras tienen en cuenta este creciente fenómeno de la reescritura en el siglo XXI y su repercusión en la sociedad y en la cultura actual.

Muy útil ha sido también la distinción que hizo M. Riffaterre al referirse a las fuentes de la intertextualidad: por un lado, la que deriva de los textos particulares y, por otro, la que deriva del sociolecto o de la sociedad y de la cultura universal. El primero está presente en los actos concretos de intertextualidad; el segundo es permanente y se encuentra siempre en todo acto de escritura, muchas veces de manera insalvable e indetectable.

Se vienen distinguiendo tres líneas en la concepción de la intertextualidad: por un lado, la defendida por J. Kristeva, J. Derrida o R. Barthes, que supone que el texto es una red de superposición y entrecruzamientos de texto interminable, entendiendo el texto como transtextualidad infinita y la intertextualidad como el factor de creación y transformación de textos. Por otro lado, la postura defendida por M. Riffaterre respecto a la lectura, como dialéctica de unos textos en otros a través del lector, lo que supone una lectura que da volumen al texto y no es una mera linealidad, en la que la intertextualidad marca esta lectura intensa. Y, por último, la de U. Eco, que define lo intertextual como una hipercodificación en la que el texto tiene elementos que pueden orientar la lectura (Ramírez, 2000: 144). 
Tomás Albaladejo, por su parte, en los últimos años y a través de distintos proyectos de investigación, está desarrollando nuevos enfoques interdisciplinares y originales respecto a distintos tipos de texto, pero centrándose fundamentalmente en los literarios. Sus propuestas respecto al análisis interdiscursivo (Albaladejo 2005; 2007a; 2007b; 2008; 2010; 2011) van en esta línea, desarrollando propuestas poéticas y retóricas aplicadas a textos muy variados. El análisis interdiscursivo, según lo desarrolla Albaladejo, es un concepto que trasciende la intertextualidad al incluir en su análisis tanto las relaciones microestructurales como las macroestructurales, en una relación discursiva integradora de ambos aspectos del texto, destacando, además, los distintos tipos de hipertextualidad que son analizados en textos correspondientes a todos los géneros literarios, con lo que el estudio interdiscursivo aporta, a mi juicio, flexibilidad a estos estudios. Igualmente sucede con sus propuestas realizadas por Tomás Albaladejo que están relacionadas con la traducción literaria y con la transducción. El marco teórico original parte de la actualización de las propuestas poéticas y retóricas clásicas que son aplicadas al estudio de la literatura comparada lo que proporciona mucho rendimiento de análisis y un marco metateórico y metaanalítico nuevo (Albaladejo 2008; 2010).

La interdiscursividad propuesta por Albaladejo, aunque tiene en cuenta el fenómeno de la intertextualidad, es distinta a ésta. Se trata de un concepto en el que se designa, por un lado, la relación que existe entre los discursos, por otro lado, la relación existente entre discursos y clases de discursos y, por último, la relación existente entre las disciplinas que se ocupan de la producción, recepción, interpretación y estudio de los discursos en una sociedad y en una cultura concreta. La intertextualidad se sitúa en la estructura microsintáctica del texto, atendiendo a la relación que se establece entre los textos respecto a las estructuras y elementos textuales de unos y otros y respecto a la transferencia de elementos temáticos presentes en los nuevos textos, ya de modo directo o indirecto. Sin embargo, el análisis interdiscursivo permite la incorporación de criterios retóricos y comparatistas al análisis de los textos literarios, y permite, a su vez, estudiar los elementos comunes y diferenciales de los textos (literarios o retóricos) mostrándose como un instrumento teórico y crítico muy eficaz en la descripción y explicación de los fenómenos textuales. Para Albaladejo (2010: 21), la interdiscursividad abarca a la intertextualidad, ya que las relaciones entre los textos, que se definen tanto por lo que son como por lo que no son, pueden existir al margen de la posible influencia detectable microestructuralmente. Albaladejo se ocupa de la relación entre discursos en distintos planos (textual, ideológico, pragmático) y también de las cuestiones de determinación del género al que pertenecen esos textos, precisamente en la relación que establecen esos discursos con cada clase de discurso. Estas clasificaciones textuales, a su vez, son clases de discurso; y por eso mismo pueden ser comparadas con otras clases de discurso, como sucede en los textos traducidos (original y traducciones), en los textos persuasivos y no persuasivos, definidos por su relación de oposición (Albaladejo 2010: 18-19).

Por supuesto que otros autores se han ocupado de estudiar la interdiscursividad también. Edmund Cros, por ejemplo, a la hora de describir el texto lo hace desde esta perspectiva de la interdiscursividad como la materialización de discursos que se relacionan como fenómenos de conciencia, o plasmaciones de estructuras ideológicas producidas en sociedad, teniendo en cuenta los códigos 
semióticos de su presentación y las actitudes e ideologías, y atendiendo a las posibles contradicciones socio-históricas del autor (Cros, 1986: 116). Para este autor también la historia y la sociedad deben ser consideradas como textos, como si se tratara de cualquier otra práctica semiótica (Cros, 1997: 122).

Ramírez Caro, por su parte, que cita y sigue las propuestas de E. Cros, define la interdiscursividad como la manifestación de la polifonía de los textos o «la expresión de la ideología y la formación discursiva de las formaciones sociales por las que atraviesa el texto» (Ramírez Caro, 2000: 137). Para este autor todo acto de habla, toda realización a través de la palabra desarrolla un interdiscurso que marca en el texto resultante inevitablemente huellas discursivas de una formación ideológica enmarcada en una formación social (Ramírez Caro, 2000: 146-147). Así pues, a este autor le interesa la lectura interdiscursiva para poder identificar las huellas de los discursos dentro de una formación ideológica y también señalar el entorno social y cultural desde el que se han generado. Es una perspectiva que pone su punto de mira en el acto de recepción, en el que el lector se convierte en una especie de texto, pues al ejercitar el acto de lectura y detectar marcas intertextuales, el lector activará textos que tiene en su memoria e interactuará con ellos, desde una perspectiva intertextual (Ramírez Caro, 2000: 149-150). Es lo que define como una lectura dialéctica, no meramente lineal, en la que el lector pasa a ser texto, como depositario de lecturas previas, a la vez que consigue detectar esas referencias que forman parte de su acervo cultural. Como puede verse, la teoría de Ramírez Caro presenta la intertextualidad como una estrategia de escritura, pero también como una metodología de lectura que supera la mera linealidad de la lectura y propone una relación de sentidos y una comprensión de los textos en su relación con otros textos (Ramírez Caro, 2000: 148-149). Esta postura se enmarca entre las expuestas por E. Cros y M. Riffaterre, al ocuparse tanto de la creación de las obras como de la recepción de las mismas:

Así como el autor no es ya un yo, sino un sujeto transindividual, un nosotros, una interpersona, el texto terminará siendo un intertexto que materializa interdiscursos, y el lector tendrá que ser un interlector (otro intertexto): cada autor se abre a otro autor, cada texto a otros textos y cada lector a otro lector-leído, a otra lectura (Ramírez Caro, 2000: 149).

José Enrique Martínez Fernández, en el citado libro (Martínez, 2001: 78), también se ocupa de este fenómeno de la interdiscursividad adjudicándoselo a las relaciones que mantiene un texto con todos los discursos registrados en una cultura y en una sociedad determinada, atendiendo a postulados ideológicos, dejando fuera las relaciones establecidas entre un texto y otro texto, que más bien serían relaciones intertextuales. Muchos autores se refieren al concepto de interdiscursividad para señalar y destacar esta dimensión ideológica (socio-ideológica y cultural) que puede verse transversalmente en muchos tipos de discurso.

Tomás Albaladejo también ha hecho una propuesta novedosa al plantear recientemente la Retórica Cultural como otro marco de estudio de la cultura, distinguiendo los Estudios Culturales de los Estudios de la Cultura. La Retórica Cultural ha sido analizada por Francisco Chico Rico (2015) como un nuevo y productivo ámbito de la Neorretórica e integra en su propia esencia epistemológica las propuestas de análisis interdiscursivo e intertextual. Así, la Retórica Cultural (2016) es una vía de 
estudio que toma de la Retórica la metodología necesaria para el análisis de la cultura en la sociedad actual. Tomás Albaladejo la define de la siguiente manera:

La Retórica es parte de la cultura y no se concibe una reflexión sobre la cultura que no preste atención a la comunicación discursiva y a su estudio; pero, además, la cultura es necesaria para el funcionamiento y la eficacia de la comunicación humana, en la medida en que ésta es llevada a cabo por productores y por receptores, que han de estar unidos por un código comunicativo y han de ser conscientes del contexto y de la necesidad de la adecuación al mismo. Retórica y cultura están unidas y no puede entenderse una sin la otra (Albaladejo, 2013).

Chico Rico (2015: 315-319) reseña los espacios a los que la Retórica Cultural presta mayor atención, en el marco del funcionamiento del discurso y de la comunicación en la sociedad y en la cultura actual: 1) el estudio del lenguaje figurado; 2) la fundamentación cultural de los diferentes lenguajes de una sociedad; 3) la dimensión intersemiótica definida por el discurso retórico; 4) el estudio de las convenciones discursivas, de obras literarias y de otras clases de discursos, y las convenciones culturales; 5) el estudio de la poliacroasis; 6) la imagen cultural que tienen los receptores de los discursos. La Retórica Cultural se basa, por lo tanto, en la dimensión retórica (desde una perspectiva persuasiva) de los elementos culturales presentes en los textos o discursos; también se basa en la consideración de la Retórica como una construcción cultural, como una ciencia y una técnica culturales que son trasmitidas de generación en generación manteniendo unos fundamentos estables, pero con modificaciones. Y abre paso a las relaciones entre los textos y de los textos con la cultura, que llevan a cabo tanto los productores como los receptores de estos textos. Y todo ello, según propone Albaladejo, se realiza con un carácter comparatista, atendiendo a semejanzas y a diferencias. La Retórica Cultural así concebida es una corriente en la investigación que se ocupa del papel funcional de la Retórica en la cultura y de sus elementos y rasgos culturales y es propuesta como un instrumento para la explicación del discurso retórico como fenómeno comunicativo ligado a la conciencia cultural de productores y receptores. Como señala Albaladejo, la Retórica Cultural «se ocupa de la semiosis del discurso retórico en sus distintas operaciones, prestando atención a las implicaciones sociales de la comunicación discursiva en los diferentes ámbitos del discurso y de la comunicación» (Albaladejo, 2007b: 8).

La Retórica Cultural se constituye en una nueva vía de acercamiento al discurso de los Estudios de la Cultura en los que están integrados también los Estudios Antropológicos y Etnográficos de la Cultura; los Estudios Culturales (Cultural Studies) anglonorteamericanos; el Análisis y la Crítica de la Cultura desarrollada en gran medida en Holanda, en la Amsterdam School of Cultural Analysis que estudia los fenómenos culturales relacionados con la comunicación y la literatura, como el mercado editorial, el papel de las nuevas tecnologías en la literatura, etc.; y la Semiótica de la Cultura, que fue desarrollada en la Escuela de Tartu (Estonia) por Yury Lotman, Boris Uspensky y su continuador Peeter Torop y que estudia la cultura desde la perspectiva de la Semiótica, explicando la obra como signo que mantiene relación con otras obras siendo distintas formas de manifestación cultural por medio de sistemas de signos verbales, visuales (pictóricos) o musicales. Junto a estas escuelas, la Retórica Cultural se propone para estudiar las relaciones de influencia entre los distintos textos y en 
114 Tropelías. Revista de Teoría de la Literatura y Literatura Comparada, número extraordinario 1 (2017) Juan Carlos Gómez Alonso

sus respectivos espacios culturales, en los que se estudia la inserción de elementos culturales tanto textuales como gestuales, dentro del sistema pragmático cultural del hecho retórico.

\section{Bibliografía}

Albaladejo, T. (2005): «Especificidad del texto literario y traducción», en C. GonZalo García, y V. GARCíA YEBRA, eds., Manual de documentación para la traducción literaria. Madrid, Arco. (2005): «Retórica, comunicación, interdiscursividad», Revista de Investigación Lingüística 8/1, pp. 7-34.

(2007a): «Semiótica, traducción literaria y análisis interdiscursivo», en M. A. GARRIDO Gallardo y E. Frechilla Díaz, eds., Teoría/Crítica. Homenaje a la Profesora Carmen Bobes Naves. Madrid, Consejo Superior de Investigaciones Científicas, pp. 61-75.

(2007b): «Traducción, discurso, sociedad», en M. V. UTRERA TORREMOCHA y M. ROMEROLUQUE, Estudios literarios in honorem Esteban Torre. Sevilla, Universidad de Sevilla, pp. 179192.

(2008): «Poética, Literatura Comparada y análisis interdiscursivo», Acta Poetica 29/2, otoño, pp. 245-275.

(2011): «Los discursos del conflicto y los conflictos del discurso. Análisis interdiscursivo y Retórica cultural», en A. G. MACEDO, C. MEndES DE SousA, V. MourA, org., Vozes, Discursos e Identidades em Conflito. Braga, Húmus - Centro de Estudos Humanísticos, Universidade do Minho, pp. 41-60.

(2012): «Literatura comparada y clases de discursos. El análisis interdiscursivo. Textos literarios y forales de Castilla y de Portugal», en R. AlEMANY FERRER y F. CHICO Rico, eds., Literaturas ibéricas medievales comparadas. Alicante, SELGYC, pp. 15-38.

(2013): «Retorica cultural, lenguaje retórico, lenguaje literario» en Tonos digital, $\mathrm{n}^{\circ} 23$, julio de 2013, http://www.tonosdigital.com/ojs/index.php/tonos/article/view/974/0 (última consulta, 4-62017).

(2016): «Cultural Rhetoric. Foundations and perspectives», Res Rethorica, 1, pp. 17- 29.

ALLEN, G. (2010): Intertextuality. Nueva York, Routledge.

BARTHES, R. (1988): «The death of the author», en R. LodGe, ed., Modern Criticism and Theory: A Reader. Londres, Longman.

Bloom, H. (2011): Anatomía de la influencia. Madrid, Taurus. (2013): La ansiedad de la influencia. Una teoría de la poesía. Madrid, Trotta.

Chico Rico, F. (2015): «La Retórica Cultural en el contexto de la Neorretórica», Dialogía: revista de lingüística, literatura y cultura, 9, pp. 304-322, http://www.journals.uio.no/index.php/Dialogia/ article/view/2597 (última consulta, 18-6-2017).

CROS, E. (1986): Literatura, ideología y sociedad. Madrid, Gredos. (1997): El sujeto cultural. Sociocrítica y psicoanálisis. Buenos Aires, Corregidor. 
DE LA RIVA FORT, J. A. (2016): Género literario y reescrituras contemporáneas de la épica homérica. Tesis doctoral, Universidad Autónoma de Madrid.

DoLEŽEL, L. (1995): Heterocósmica. Madrid, Arco Libros.

Foucault, M. (1979): «What is an Author», Screen, 20, pp. 13-33.

GENETTE, G. (1989): Palimpsestos. La literatura en segundo grado. Madrid, Taurus.

GÓMEZ-MorianA, A. (1997) «Du texte au discours. Le concept d'interdiscursivité», Versus, 77-78, pp. 57-73.

Kristeva, J. (1967): «Bajtin, le mot, le dialogue et le roman», Critique, 239.

- (1974): El texto de la novela. Barcelona, Lumen.

MARTínez FERnÁNDEZ, J. E. (2001): La intertextualidad literaria (Base teórica y práctica). Madrid, Cátedra.

PANZIERI, F. (1996): «Variazioni da un'anticamera postmoderna. Scenari \& trend della narrativa italiana tra anni Ottanta e Novanta», en R. CARDONE, F. GALATO, F. PANZIERI, eds., Altre storie. Milán, Marcos y Marcos, pp. 15-52.

RAMÍREZ CARO, J. (2000): «Lecturas intertextual e interdiscursiva en sociocrítica», Letras, 32, pp. 137 161.

SANDERS, J. (2008): Adaptation and appropriation. Nueva York, Routledge. 